Supplemental information:

\title{
Four decades of United States mobile source pollutants: spatial-temporal trends assessed by ground-based monitors, air quality models, and satellites
}

\author{
Lucas RF Henneman ${ }^{1 *}$ \\ Huizhong Shen ${ }^{2}$ \\ Christian Hogrefe $e^{3}$ \\ Armistead G Russell ${ }^{2}$ \\ Corwin M Zigler ${ }^{4}$
}

${ }^{1}$ George Mason University Department of Civil, Environmental, and Infrastructure Engineering, Fairfax, VA

${ }^{2}$ Georgia Institute of Technology School of Civil and Environmental Engineering, Atlanta, GA

${ }^{3}$ Atmospheric Dynamics and Meteorology Branch; Atmospheric and Environmental Systems Modeling Division;

CEMM, ORD, U.S. EPA; Research Triangle Park, NC

${ }^{4}$ University of Texas Department of Statistics and Data Sciences and Department of Women's Health, Austin, TX

*Corresponding author; Ihennem@gmu.edu; 4400 University Drive, MS-6C1, Fairfax, VA 22030

In this document:

12 Pages

15 Figures

1 Table 


\section{Supplemental material}

Table SI - 1: Data sources employed in the present study.

\begin{tabular}{lllll}
\hline Source & Description & Pollutants & Years & Citation \\
\hline Observations & $\begin{array}{l}\text { Ground-based } \\
\text { monitors }\end{array}$ & $\begin{array}{l}\mathrm{NO}_{2}, \mathrm{NO}_{\mathrm{x}}, \\
\mathrm{CO}, \mathrm{EC}\end{array}$ & $1995-2016$ & $\begin{array}{l}\text { EPA Air Quality System } \\
\text { (https://www.epa.gov/aqs) }\end{array}$ \\
\hline CMAQ & $36 \mathrm{~km}$ resolution & $\begin{array}{l}\mathrm{NO}_{2}, \mathrm{NO}_{\mathrm{x}}, \\
\mathrm{CO}, \mathrm{EC}\end{array}$ & $1990-2010$ & Astitha et al. 20171 \\
\hline CMAQ & $12 \mathrm{~km}$ resolution & $\begin{array}{l}\mathrm{NO}_{2}, \mathrm{NO}_{\mathrm{x}}, \\
\mathrm{CO}, \mathrm{EC}\end{array}$ & $2002-2014$ & CMAS Center 2020 \\
\hline $\begin{array}{l}\text { OMI } \\
\text { Satellite }\end{array}$ & $0.125^{\circ}$ resolution & $\mathrm{NO}_{2}$ & $2005-2019$ & Boersma, 2018 \\
\hline $\begin{array}{l}\text { Merged } \\
\text { Satellite }\end{array}$ & $0.25^{\circ}$ resolution & $\mathrm{NO}_{2}$ & $1997-2016$ & Georgoulias et al. 20194 \\
\hline $\begin{array}{l}\text { MOPITT } \\
\text { Satellite }\end{array}$ & $1^{\circ}$ resolution & $\mathrm{CO}$ & $2001-2018$ & Deeter et al. 2003 \\
\hline
\end{tabular}

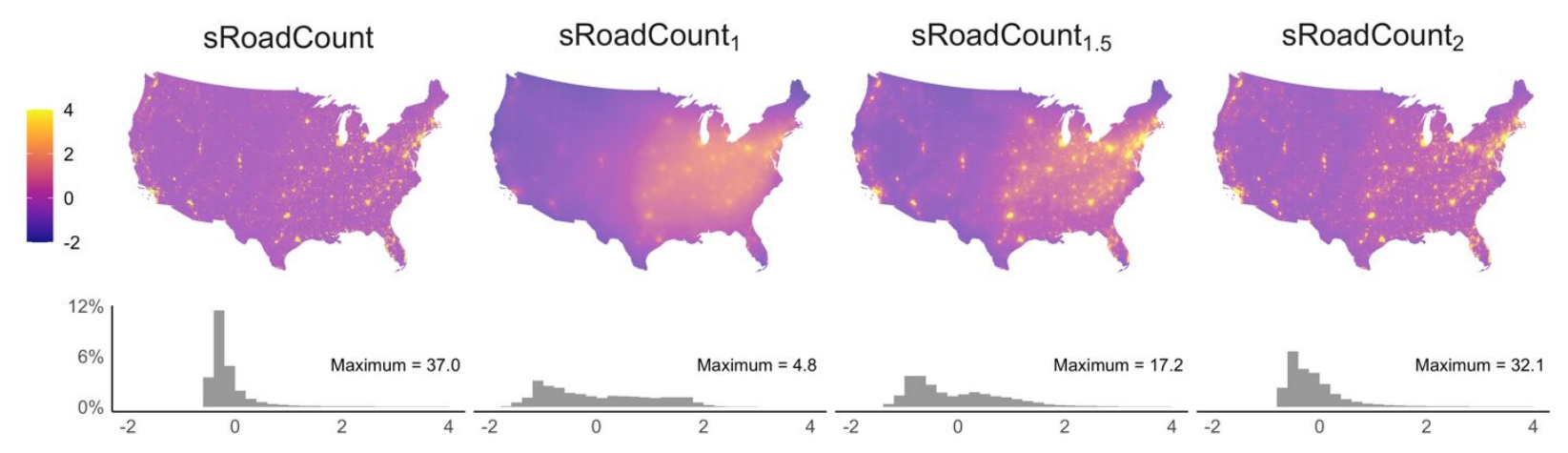

Figure SI - 1: Four definitions of road proximity based on road segment counts on a $4 \mathrm{~km}$ grid. 


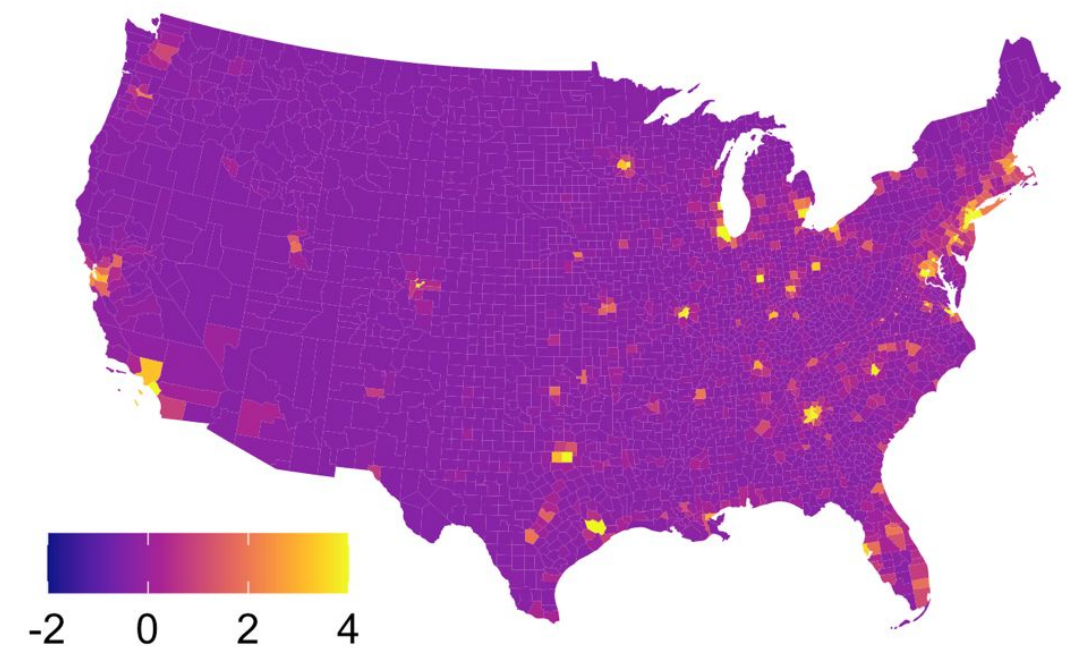

Figure SI - 2: Scaled and centered county-level vehicle miles traveled (VMT) from the 2017 National Emissions Inventory.
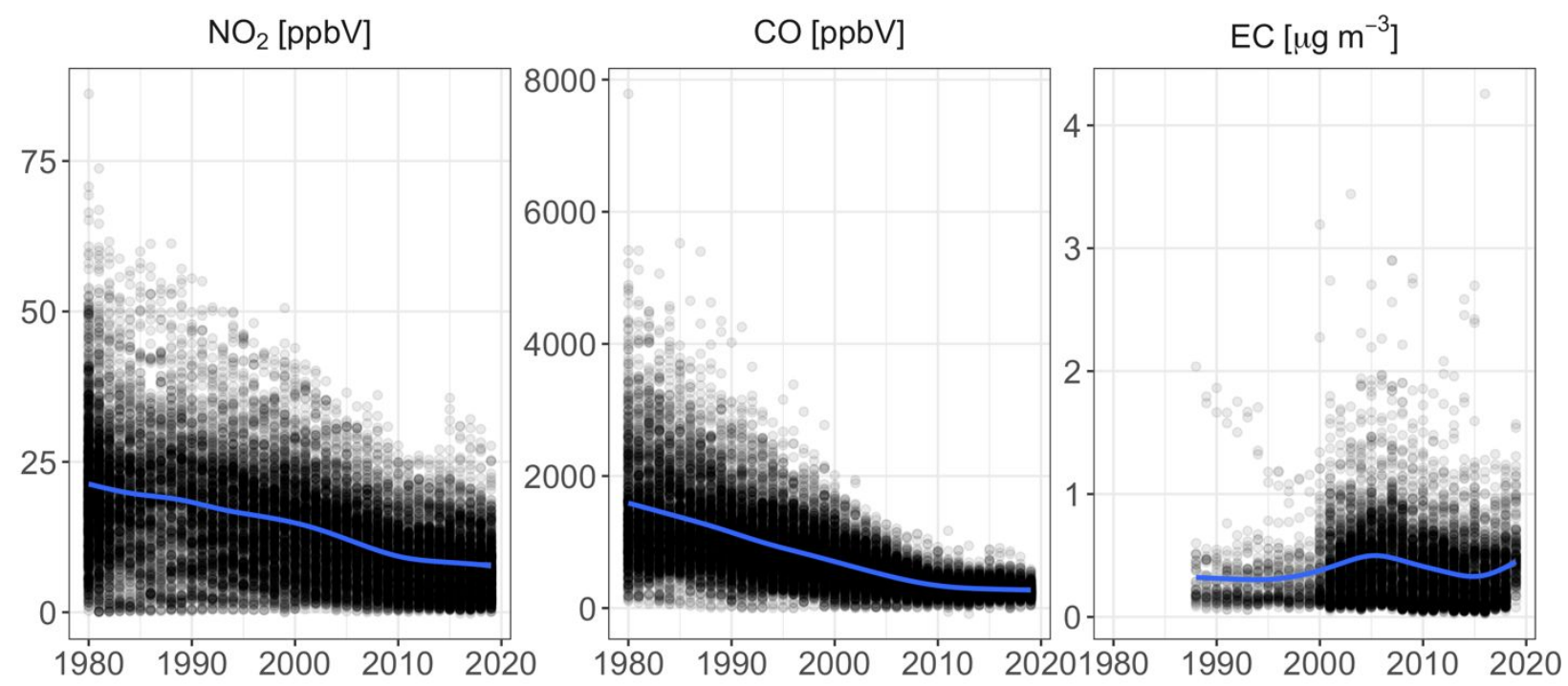

Figure SI - 3: Observed annual concentrations at all monitor locations. The blue line denotes a smooth cubic spline fit to the data. 

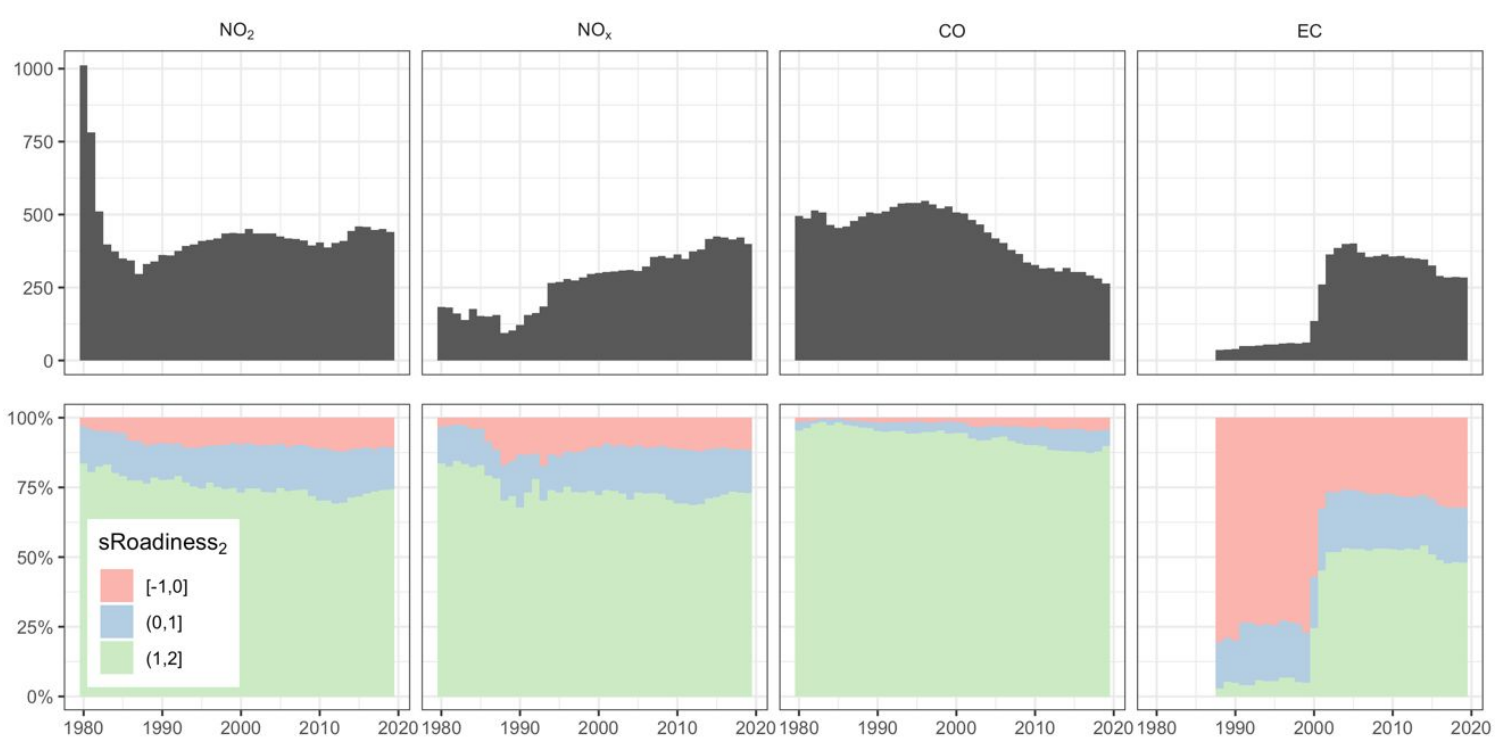

Figure SI - 4: annual numbers of monitors reporting observations (top) and their distribution by sRoadiness $_{2}$ (bottom).
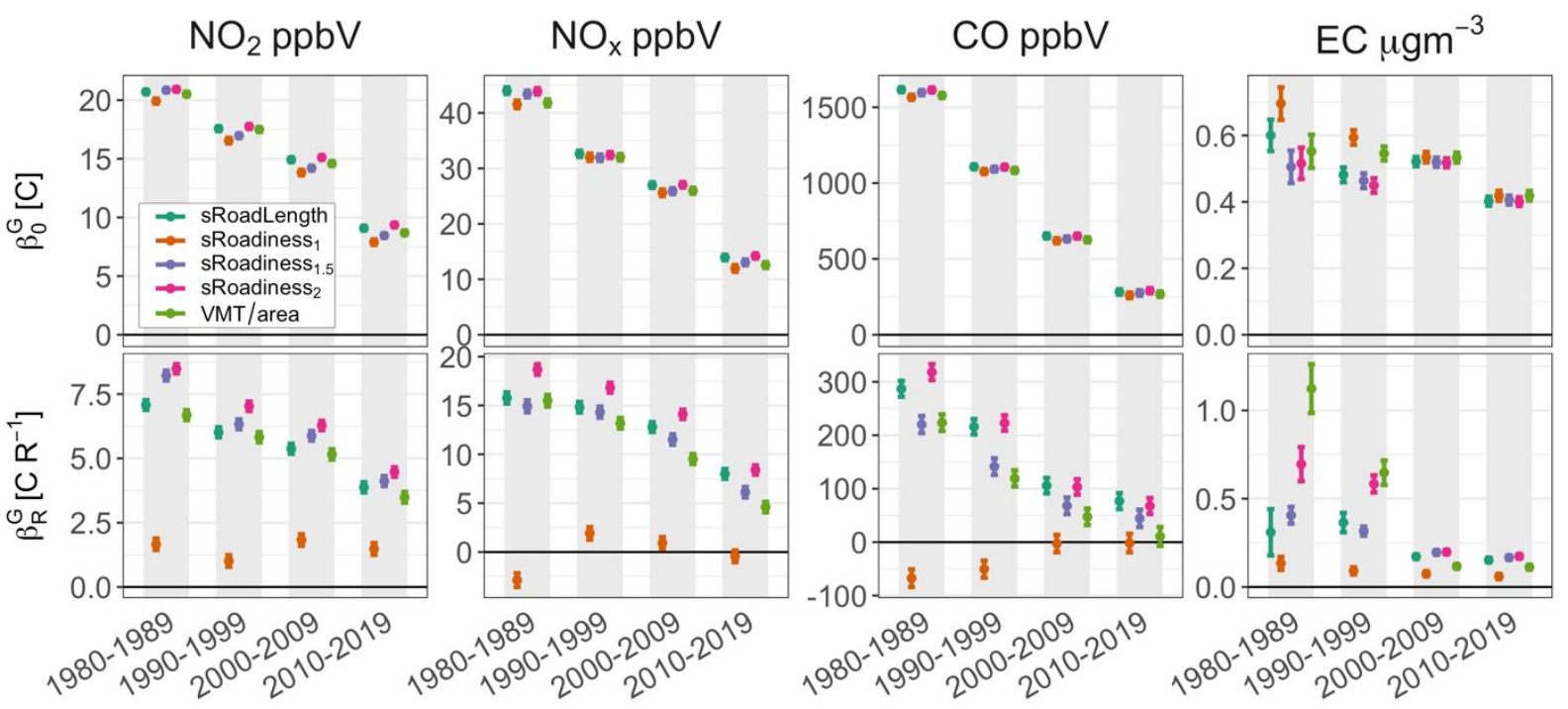

Figure SI - 5: Top - average concentrations $\left(\beta_{0}^{G}\right)$ for each decade group in areas with average meteorological and road proximity characteristics from equation 2. Bottom-national average change in concentration with unit increase in each definition of road proximity $\left(\beta_{R}^{G}\right)$. Both metrics are interpretable at $t^{G}=0$. Error bars denote standard errors. Equation 2 was run separately for each definition of [length-based] road proximity and pollutant. 

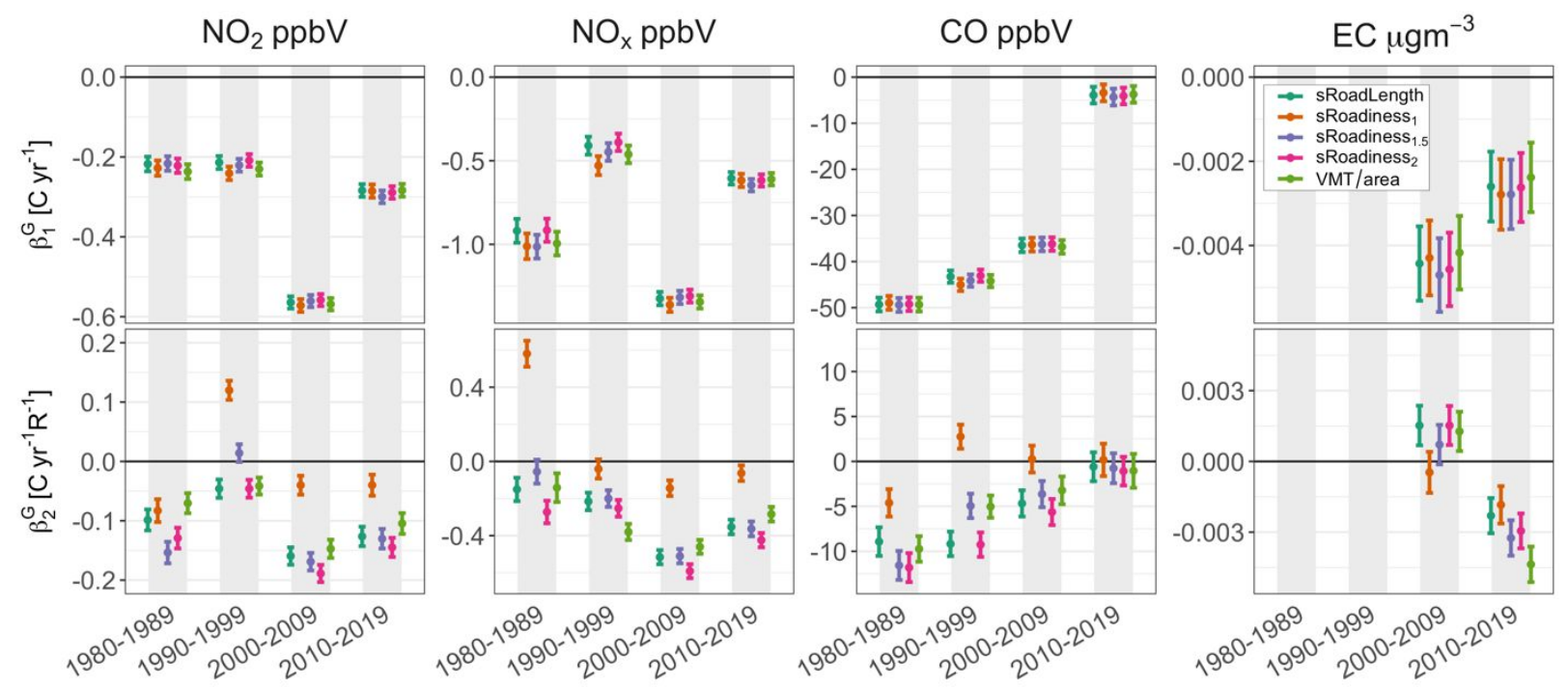

Figure SI - 6: Annual concentration change ( $\beta_{1}^{G}$; top) in areas with average meteorological and relationship with road proximity over time ( $\beta_{2}^{G}$; bottom) for observations in four decade groups. for observations in four decade groups. Error bars denote standard errors. Equation 2 was run separately for each definition of [length-based] road proximity and pollutant.
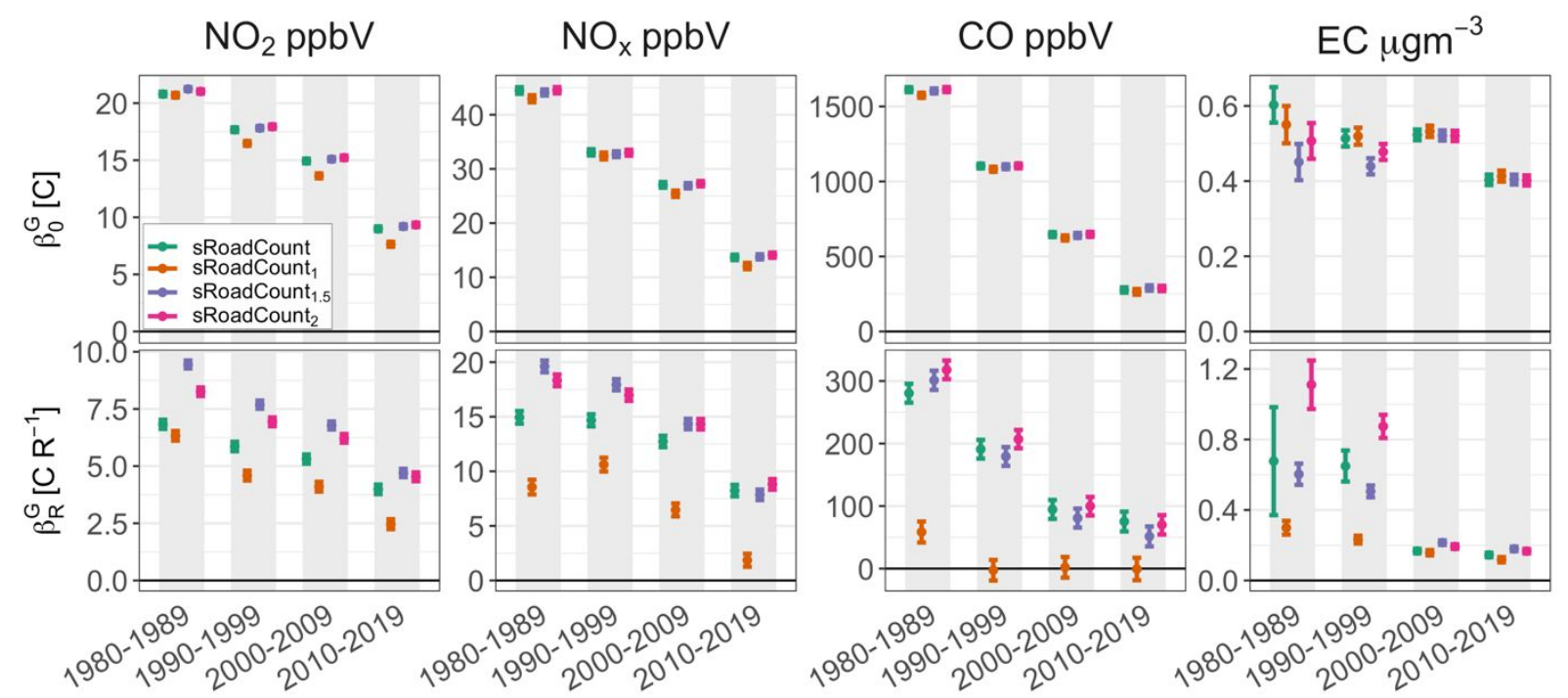

Figure SI - 7: Top - average concentrations $\left(\beta_{0}^{G}\right)$ for each decade group in areas with average meteorological and road proximity characteristics from equation 2. Bottom-national average change in concentration with unit increase in each definition of road proximity $\left(\beta_{R}^{G}\right)$. Both metrics are interpretable at $t^{G}=0$. Error bars denote standard errors. Equation 2 was run separately for each definition of [count-based] road proximity and pollutant. 


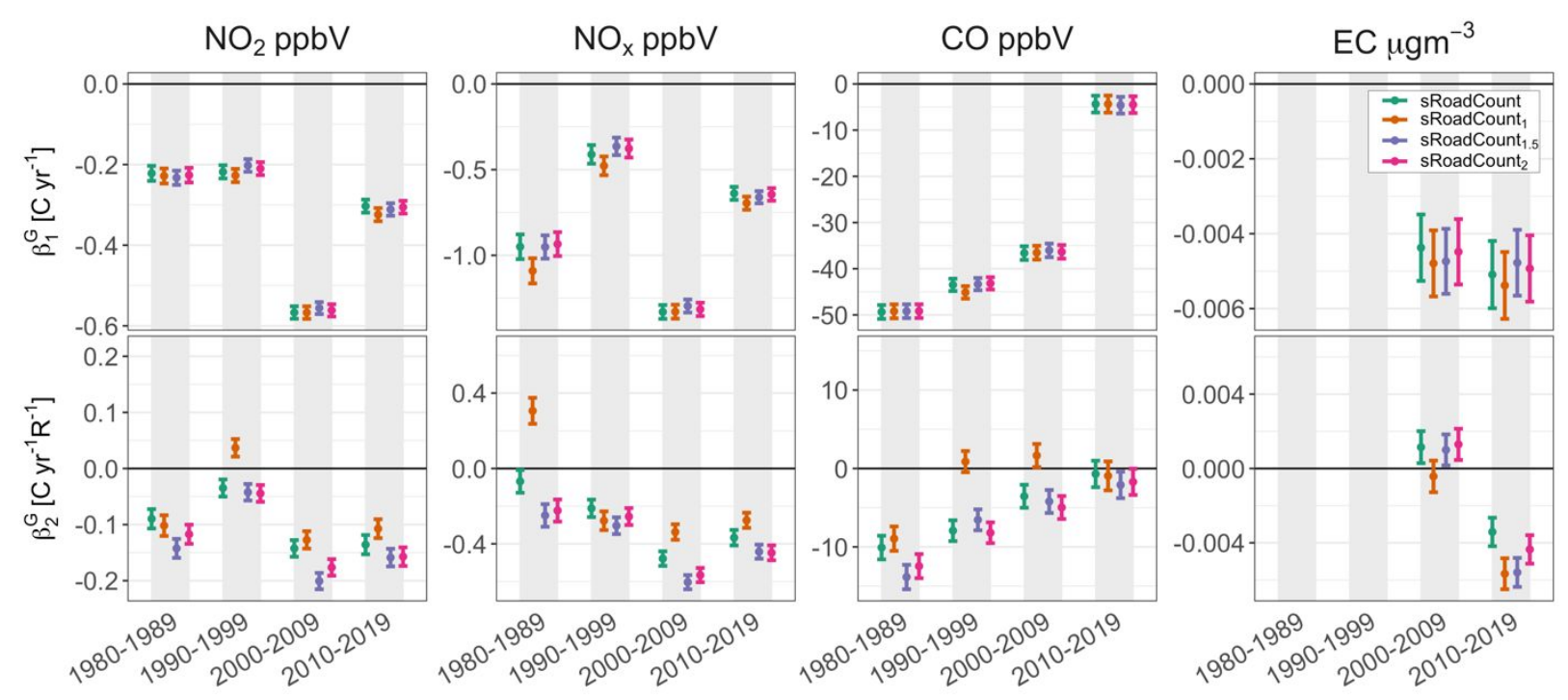

Figure SI - 8: Annual concentration change $\left(\beta_{1}^{G}\right.$; top) in areas with average meteorological and relationship with road proximity over time $\left(\beta_{2}^{G}\right.$; bottom) for observations in four decade groups. for observations in four decade groups. Error bars denote standard errors. Equation 2 was run separately for each definition of [count-based] road proximity and pollutant. 


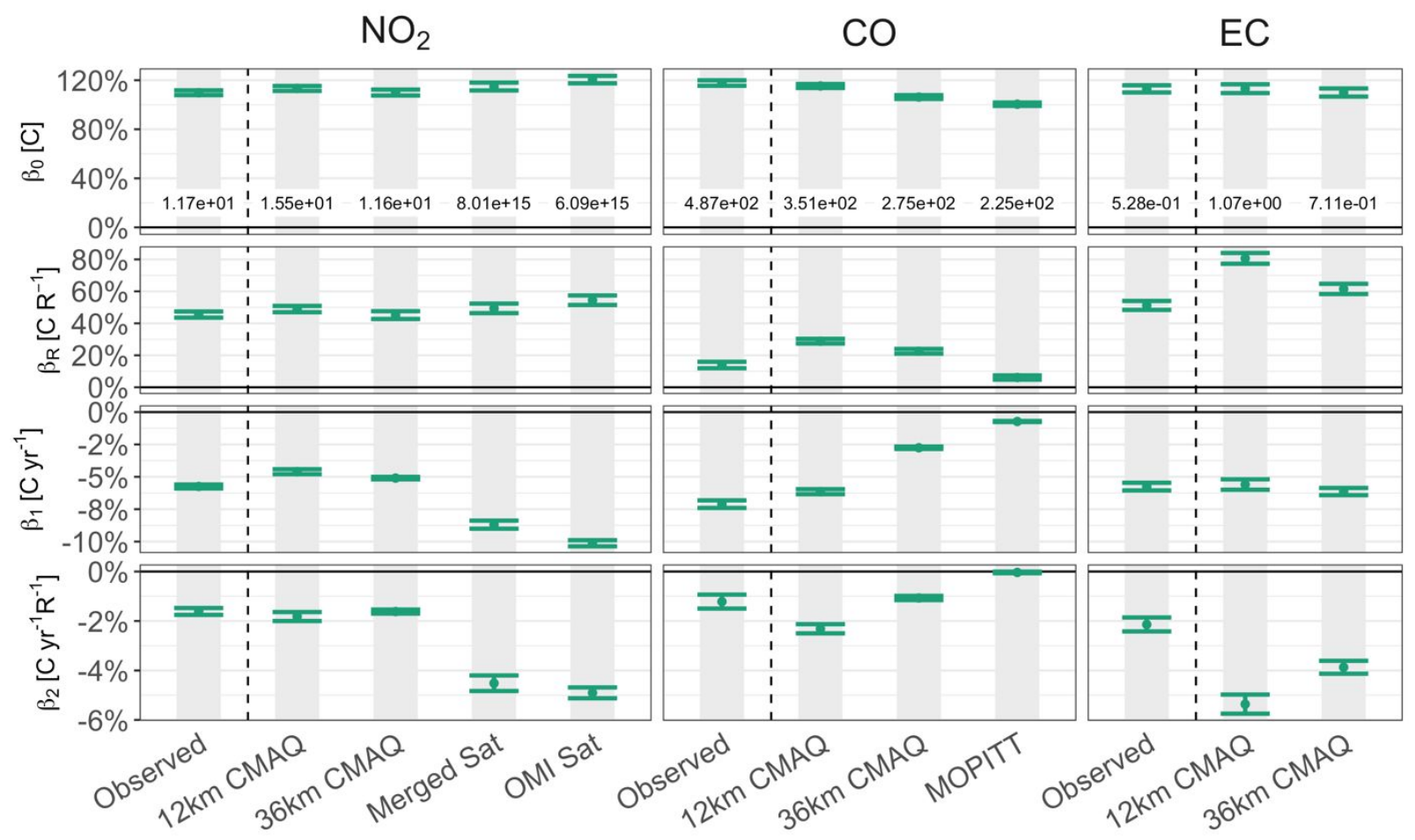

Figure SI - 9: Regression parameters from equation 2 run for each combination of pollutantmetric (horizontal axis) across 2005-2010 using sRoadiness 2 . Parameters are presented as percent of the period average for each pollutant metric. Numbers printed in the top row correspond to the raw $\beta_{0}$ with concentration units of ppbV for $\mathrm{NO}_{2}$ and $\mathrm{CO}$ except in the $\mathrm{NO}_{2}$ satellite metrics [molecules $\left.\mathrm{cm}^{-3}\right]$ and EC $\left[\mu \mathrm{g} \mathrm{m}^{-3}\right]$. Error bars denote standard errors. 


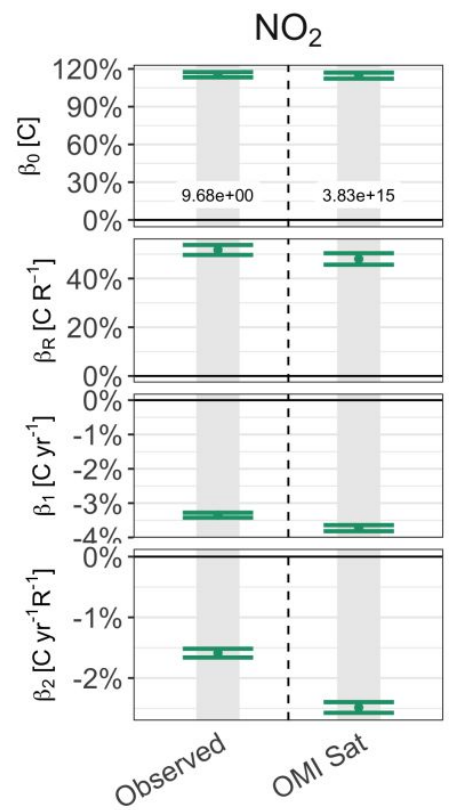

Figure SI - 10: Regression parameters from equation 2 run for observed and $\mathrm{OMINO} \mathrm{N}_{2}$ across 2011-2019 using sRoadiness 2 . Parameters are presented as percent of the period average for each pollutant metric. Numbers printed in the top row correspond to the raw $\beta_{0}$ with concentration units of ppbV for observations and molecules $\mathrm{cm}^{-3}$ for OMI. Error bars denote standard errors. 


\section{Column}

molecules $\mathrm{cm}^{-2}$
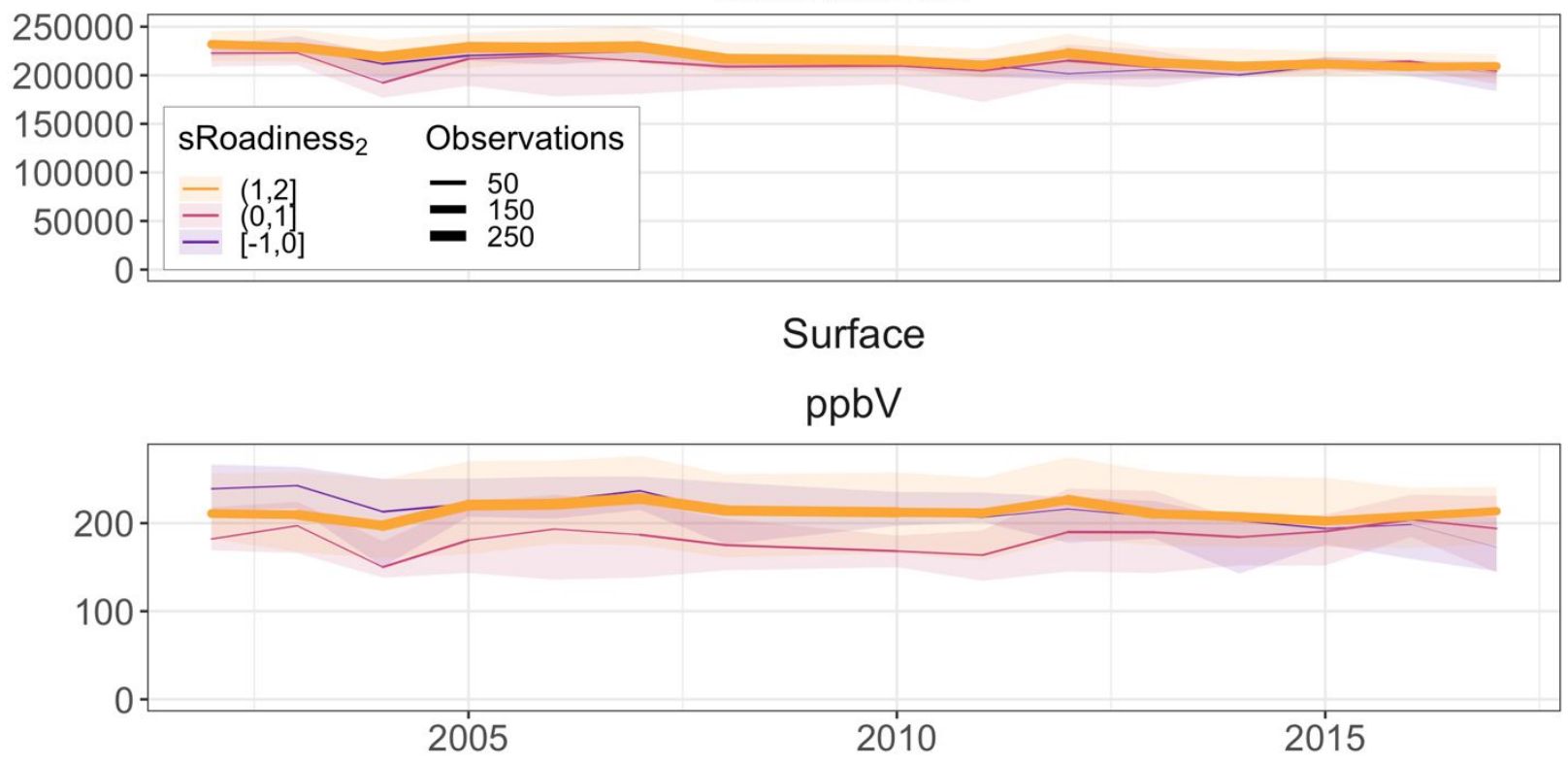

Figure SI - 11: CO concentrations as reported by two MOPITT products by sRoadiness 2 at monitor locations in the continental United States. The "Surface" metric plotted here is also plotted in Figure 2. Shaded area represents the interquartile range across monitor locations for each year.

\section{Model evaluation}

We present plots of residuals against fitted values to ensure we meet necessary model assumptions. The finding that the residuals do not show a distinct pattern provides evidence that the model does not suffer from any obvious misspecification and is appropriate for establishing relationships between concentration, time, and road proximity.
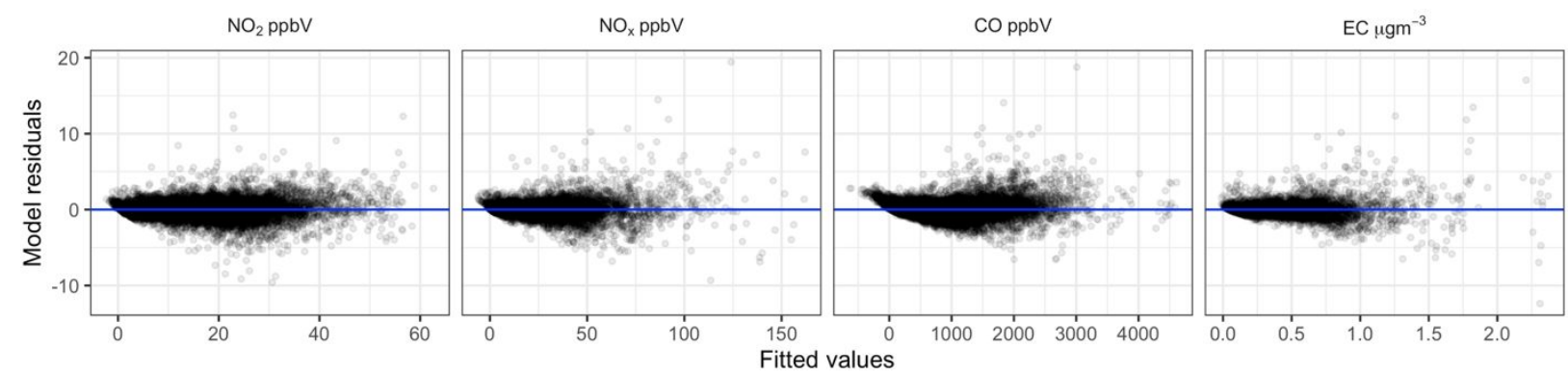

Figure SI - 12: Model residuals against fitted values for models presented in Figures 3 and 4. 

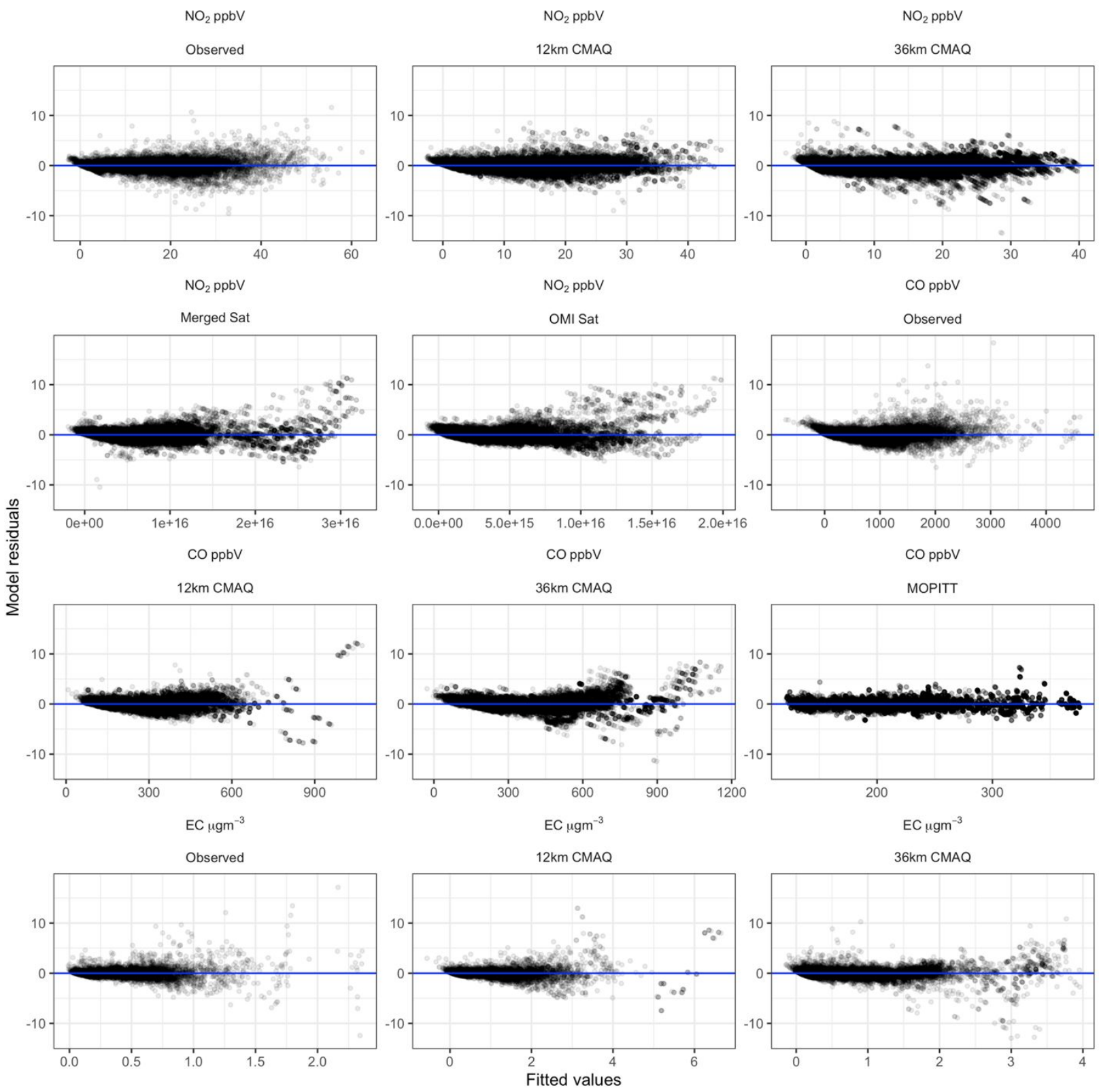

Figure SI - 13: Model residuals against fitted values for models presented in Figure 5. 

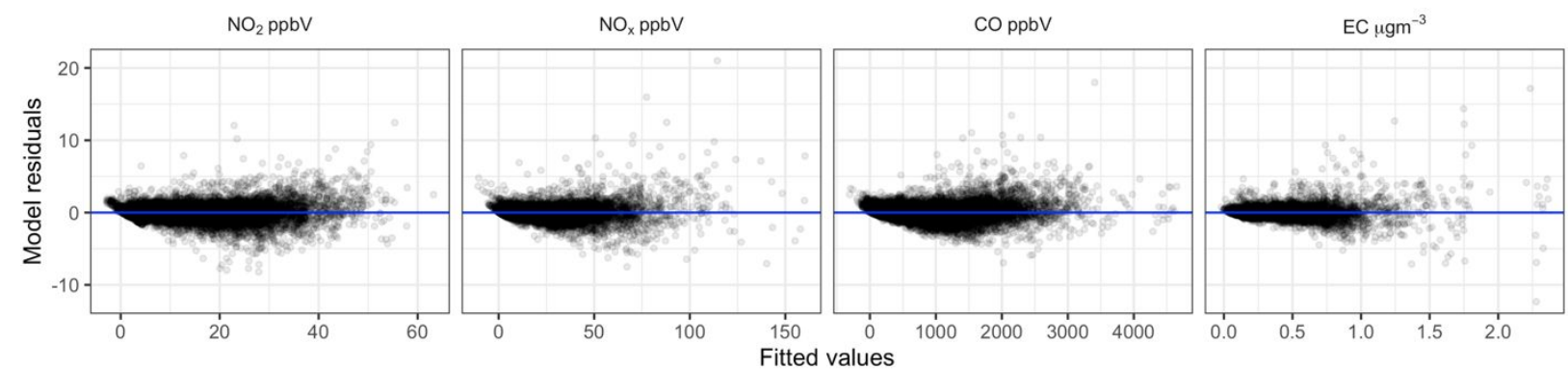

Figure SI - 14: Model residuals against fitted values for models presented in Figures 6 and 7.

We add a sensitivity analysis that removes meteorology terms as predictors to test their potential to confound our estimated relationships (Figure SI-15). The coefficients of interest are very similar in the main model and the sensitivity analysis (except in the case of parameters representing the early years of EC measurements without many observations), which suggests that the concentration-time-road proximity relationships are not substantially confounded by annual meteorological variability.
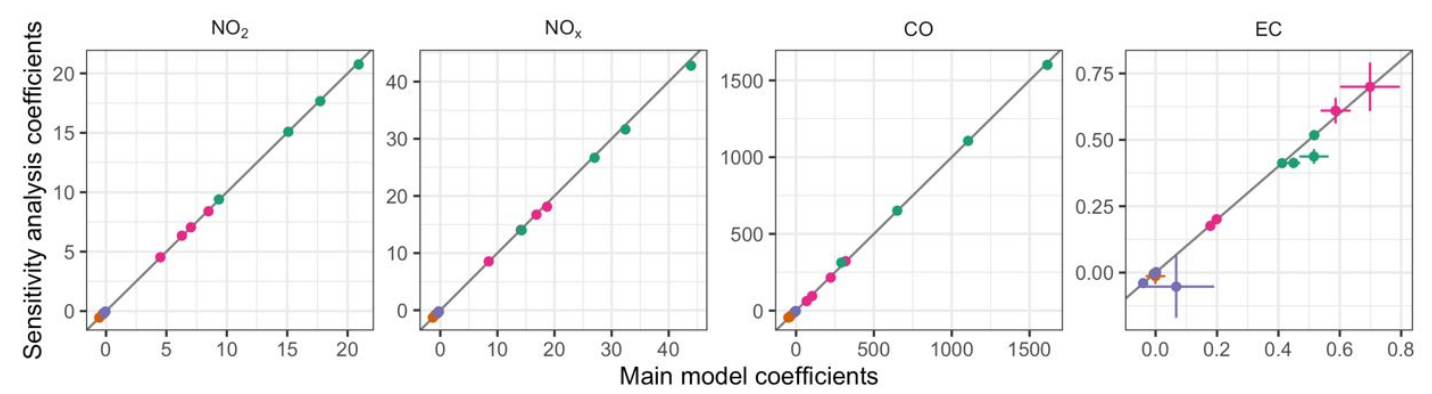

$\rightarrow \quad \beta_{0}[\mathrm{C}]$

$\rightarrow \beta_{1}\left[\mathrm{C} y \mathrm{r}^{-1}\right]$

$\rightarrow \beta_{2}\left[C y r^{-1} R^{-1}\right]$

$\rightarrow \quad \beta_{R}\left[\mathrm{CR}^{-1}\right]$

Figure SI - 15: Model coefficients of interest in two modeling platforms: the main model (model 2; horizontal axis) and a sensitivity analysis with all meteorological terms removed for the observation-based models presented in Figures 3 and 4. Error bars denote standard errors. 


\section{References}

(1) Astitha, M.; Luo, H.; Rao, S. T.; Hogrefe, C.; Mathur, R.; Kumar, N. Dynamic Evaluation of Two Decades of WRF-CMAQ Ozone Simulations over the Contiguous United States. Atmos. Environ. 2017, 164, 102-116. https://doi.org/10.1016/j.atmosenv.2017.05.020.

(2) CMAS Center. CMAS Data Warehouse https://dataverse.unc.edu/dataverse/cmascenter (accessed Jul 16, 2020).

(3) Boersma, K. F.; Eskes, H. J.; Richter, A.; De Smedt, I.; Lorente, A.; Beirle, S.; Van Geffen, J. H. G. M.; Zara, M.; Peters, E.; Van Roozendael, M.; Wagner, T.; Maasakkers, J. D.; Van Der A, R. J.; Nightingale, J.; De Rudder, A.; Irie, H.; Pinardi, G.; Lambert, J. C.; Compernolle, S. C. Improving Algorithms and Uncertainty Estimates for Satellite NO2 Retrievals: Results from the Quality Assurance for the Essential Climate Variables (QA4ECV) Project. Atmos. Meas. Tech. 2018, 11, 6651-6678.

https://doi.org/10.5194/amt-11-6651-2018.

(4) Georgoulias, A. K.; Van Der, R. A. J.; Stammes, P.; Folkert Boersma, K.; Eskes, H. J. Trends and Trend Reversal Detection in 2 Decades of Tropospheric NO2 Satellite Observations. Atmos. Chem. Phys. 2019, 19, 6269-6294. https://doi.org/10.5194/acp-196269-2019.

(5) Deeter, M. N.; Emmons, L. K.; Francis, G. L.; Edwards, D. P.; Gille, J. C.; Warner, J. X.; Khattatov, B.; Ziskin, D.; Lamarque, J. F.; Ho, S. P.; Yudin, V.; Attié, J. L.; Packman, D.; Chen, J.; Mao, D.; Drummond, J. R. Operational Carbon Monoxide Retrieval Algorithm and Selected Results for the MOPITT Instrument. J. Geophys. Res. D Atmos. 2003, 108 (D14). https://doi.org/10.1029/2002jd003186. 